\title{
MAMITE BOVINA DEVIDA A LEVEDURA DO GÊNERO CANDIDA
}

Eduardo do Nascimento MÓS(*)

Eduardo H. BIRGEL (**)

Wanderley Pereira de ARAÚJO (**)

Maria José Soares MENDES (***)

RFMV-A/22

MOS, E.N.; BIRGEL, E.H.; ARAUJO, W. P.; MENDES, M. J. S. Mamite bovina devida a levedura do gênero Candida. Rev. Fac. Med. Vet. Zootec. Univ. S. Paulo, 15 (2): -, 161-64, 1978

RESUMO: Os autores apresentam um caso de mastite em animal da espécie bovina, raça holandeza, preto e branco, 8 anos de idade, importado do Canadá e de alta produção. É referido como antecedentes, traumatismo ao nivel da glândula mamária, com aumento de volume $e$ mamite dos quartos direitos. Após tratamento durante cinco (5) dias com oxacilina houve exacerbação dos sintomas. O diagnóstico se estabeleceu pelo cultivo de material dos quartos confirmando quadro de mamite por leveduras do gênero Candida. Os resultados parciais das provas bioquimicas sugerem tratar-se da espécie Candida luzitanae.

UNITERMOS: Mamite Candida Luzitanae *, Levedura.

\section{INTRODUÇÃO}

Embora as leveduras vivam saprofiticamente sobre frutas, produtos de leiteria, pele $\mathrm{e}$ intestinos do homem $\mathrm{e}$ animais ${ }^{(3)}$ podem causar inflamaçöes de caráter benigno em bovinos com diminuição da produção leiteira além de as vezes perdurarem por longos períodos de tempo ${ }^{(6)}$ ou curarem espontaneamente ${ }^{(13)}$. Estas se verificariam pela lesão do epitélio mamário, além do estímulo causado pela antibioticoterapia, uma vez que leveduras do gênero Candida utilizam a Penicilina e a Tetraciclina como fontes de Nitrogênio ${ }^{(7,11,12)}$. Para outros ${ }^{(2)}$ elas seriam causadas pela alergia medicamentosa causada pelo antibiótico que sensibilizaria o local das mucosas, pelo desequilíbrio micobacteriano causado por ação do antibiótico sobre o crescimento das leveduras (aureomicina) ou pela destruição da microbiota bacteria- na antagônica das leveduras o que favoreceria seu desenvolvimento. Em razão destas leveduroses se constituírem em processos freqüentes e por se tratar o agente ora proposto raro, é que descrevemos o presente trabalho.

\section{RESENHA CLÍNICA}

Animal da espécie bovina, raça holandesa, preto e branco, 8 anos de idade, importado do Canadá e de alta produção. Como antecedente é referido: traumatismo ao nivel da glândula mamária com aumento de volume e mamite dos quartos direitos. Após aplicação de oxacilina durante cinco (5) dias, houve acerbação dos sintomas locais. Segundo o "Sistema Diagnóstico" utilizado para diagnóstico de mamites, do Departamento de Patologia e Clínica Médica da Faculdade de Medicina Veterinária e Zootecnia da Universidade de

(*) Professor Livre Docente - Instituto de Ciências Biomédicas USP (**) Professor Adjunto - Fac. de Med. Veterinária e Zootecnia USP (*) Auxiliar de Ensino - Fac. de Med. Veterinária e Zootecnia USP (***) Bioquímica Farmacêutica - Faculdade de Medicina - USP 
São Paulo, foi elaborado o seguinte quadro:

\begin{tabular}{|c|c|c|c|c|}
\hline Quarto & Palpação & Aspecto & CMT & Células \\
\hline AE & II & S.A. & - & S.A. \\
PE & II & S.A. & $(+)$ & S.A. \\
AD & V elast. & C.D. & +++ & +-+ \\
PD & V elast. & B & ++ & -+- \\
\hline
\end{tabular}

AE - Anterior esquerdo

PE - Posterior esquerdo

$A D$ - Anterior direito

PD - Posterior direito

CD - Grumos grandes e abundantes

B - Grupos pequenos em pequena quantidade. Quantidade de gordura três vezes o normal.

CMT - Californian mastitis test - avaliaçāo do $n^{\circ}$ de leucócitos +++- Grande quantidade de leucócitos.

II - Consistência normal.

$\checkmark$ - Endurecimento Difuso porém Elástico.

S.A. - Sem alteraçāo.

Células - Sedimento celular do leite leucócitos e células de descamação (com células fagocitárias). †-†- células fagocitadas de levedura.

\section{MATERIAL E MÉTODOS}

\section{Material}

1.1. Leite

Amostras de leite colhidas dos quartos afetados, previamente lavados e desinfetados eram recolhidas em Erlenmeyers estéreis com capacidade para $50 \mathrm{ml}$, no volume de $20 \mathrm{~cm}^{3}$.

1.2. Meios de cultura

Foram utilizados os seguintes meios de cultura:

1.2.1. Ágar-Sabouraud (Difco) com cloranfenicol-10 $\mathrm{mg} / \mathrm{ml}$.

1.2.2. Água peptonada com extrato de levedura e glicose.

1.2.3. Meios para o teste de fermentação. Água de peptona em vol. de $10 \mathrm{ml}$, em tubos de $10 \times 100 \mathrm{~mm}$ contendo tubos de Durhan, $\mathrm{pH} 7.2$ adicionada de solução a $20 \%$ dos seguintes açúcares: glicose, maltose, lactose, galactose, sacarose, celobiose, trealose, melibiose, rafinose e inulina.

1.2.4. Soro bovino: indicado para verificar a formação de tubos germinativos. Tubos de $10 \times 75$ mm contendo de 0,2 a $0,3 \mathrm{ml}$ de soro bovino.

1.2.5. Uréia. Uréia ágar-base (Difco) em tubos de $10 \times 1000 \mathrm{~mm}$, inclinado.

1.2.6. Fontes de carbono e nitrogênio para o teste de assimilação. d. galactose, eritritol, ribitol, L. ramnose, rafinose, celobiose, inositol, glicose, maltose, lactose, melibiose e nitrato de potássio.

\section{MÉTODOS}

\subsection{Coleta do leite}

Em volume de $20 \mathrm{ml}$, colhido assepticamente após desinfecção das mamas com álcool iodado, desprezando-se os dois primeiros jatos.

2.2. Para o isolamento, foi usado o meio de ágar-Sabouraud com cloranfenicol, inoculado na quantidade de $0,04 \mathrm{ml}$ com o auxílio de alça de platina graduada para tal volume. Semeadas em duplicata com incubação em temperatura ambiente e a $37^{\circ} \mathrm{C}$. Após 2 a 3 dias verificou-se a presença de crescimento cremoso. Através do preparo de esfregaços fixados e corados pelo método de Gram,confirmava-se a morfologia e seguiase a metodologia proposta por LODDER (10), para a classificação.

2.3. Repicava-se o material em água peptonada com extrato de levedura e dextrose e após 2,3 dias a $25^{\circ} \mathrm{C}$,faziam-se esfregaços e verificava-se a morfologia da levedura através do método de Gram.

2.4. Produção de pseudomicélio, clamidosporos e blastosporos. O meio de "Corn Meal Ágar"' (Difco) com "Tween 80" (C. Erba) a $1 \%$ é adequado para a produção de pseudomicélio e clamidosporos. A técnica adotada foi a de cultivo em lâmina, colocando-se sobre lâminas estéreis em placas de Petri, aproximadamente $1 \mathrm{~cm}^{3}$ de meio de cultura fundido; após solidificação do meio era feita a semeadura em talhes ou cortes 
paralelos, distantes alguns milímetros e, sobre estes, era colocada uma lamínula estéril. Depois de 2 a 10 dias de incubação a $25^{\circ} \mathrm{C}$, as culturas foram examinadas com pequeno aumento, através de placa fechada e com o aumento maior. A maioria das leveduras do gênero produzem pseudomicélio. Quando a espécie produz clamidosporo sua ocorrência é simultânea.

2.5. Provas de fermentação. Os meios semeados foram contidos em tubos vedados com tampas e mantidos durante 10 dias à temperatura de $25^{\circ} \mathrm{C}$. As provas positivas foram indicadas pela presença de gás. Usaram-se os seguintes carboidratos: glicose, galactose, sacarose, maltose, celobiose, trealose, lactose, melibiose, rafinose e inulina.

2.6. Provas de assimilação: Auxanógrama. (Prova para assimilação do carbono).

2.6.1.Preparado de acordo com LACAZ e cols. ${ }^{(8)}$ (1973).

Fundir em banho-maria o meio de cultura para assimilação do carbono-Meio " $\mathrm{C}$ ", em tubos de ensaio e esfriados à temperatura de $40-45^{\circ} \mathrm{C}$. No fundo das placas de Petri, marcadas com lápis vitrográfico,os açúcares que serão utilizados. Suspensão da cultura (pura e recente) em água destilada estéril adicionada nas placas de Petri em volume de aproximadamente $1 \mathrm{~cm}^{3}$. Verter o meio de base no volume de $20 \mathrm{ml}$ e homogeneizar bem com a suspensão. Colocar sobre os pontos marcados discos de cada açúcar e levar à estufa a $25^{\circ} \mathrm{C}$, durante 48 a 72 horas, faz-se a leitura cuja prova positiva é dada pelo halo de crescimento ao redor do disco de papel.

2.6.2. Prova para assimilação de fontes nitrogenadas: Seguiu-se a mesma técnica adotada para as fontes de carbono, utilizando-se porém o meio base
"N". Como fontes de nitrogênio; nitrato de potássio e sulfato de amônio (este último para fins comparativos).

\section{RESULTADOS}

Pelo exame das tabelas observou-se que a levedura isolada apresentou comportamento que sugere tratar-se da espécie Candida luzitanae, quando submetida às provas de fermentação dos carboidratos, empregados na utilização de fontes de carbono e nitrogênio, formação de pseudomicélio e tubo germinativo, produção de clamidosporos e prova da urease.

\begin{tabular}{|l|c|c|c|c|c|}
\hline \multicolumn{7}{|c|}{ Tabela I } \\
\hline Provas & & T.G. & CL & P.S. & UREASE \\
\hline Glicose & + & N & N & & \\
Sacarose & + & $\bar{A}$ & $\bar{A}$ & - & N \\
Galactose & + & O & O & - & E \\
Celobiose & + & & & - & G \\
Trealose & + & P & P & POS. & A \\
Rafinose & + & R & R & B.V. & T \\
Melibiose & - & O & O & & V \\
Lactose & - & D & D & & O \\
Maltose & - & U & U & & \\
Inulina & - & Z & Z & & \\
\hline
\end{tabular}

Legenda

$F$ - Fermentação

T.G. - Tubo Germinativo

CL - Clamidosporos

P.S. - Pseudomicélio

POS. B.V. - Positivo com blastosporos verticilados

C- Carbono

\begin{tabular}{|c|c|}
\hline \multicolumn{2}{|c|}{ TABELA II } \\
\hline Fonte PROVA & ASSIMILAÇĀO \\
\hline $\begin{array}{l}\text { D. Galactose } \\
\text { Eritritol } \\
\text { Ribitol } \\
\text { L. Ramnose } \\
\text { Rafinose } \\
\text { Celobiose } \\
\text { Inositol } \\
\text { Glicose } \\
\text { Sacarose } \\
\text { Maltose } \\
\text { Lactose } \\
\mathrm{Melibiose} \mathrm{NO}_{3}\end{array}$ & $\begin{array}{l}+ \\
- \\
+ \\
+ \\
- \\
+ \\
- \\
+ \\
+ \\
+ \\
-\end{array}$ \\
\hline
\end{tabular}




\section{DISCUSSAO E CONCLUSAOO}

ALVARES \& FLORES (1962) "' citam que entre os agentes de mamites micóticas $69 \%$ são representados por fungos leveduriformes, havendo entre estes prevalência das leveduras do gênero CANDIDA. Neste gênero, os agentes mais comuns de mamites em bovinos são: Candida albicans, Candida Krusei e Candida tropicalis ${ }^{(7)}$. Coincidentemente observou-se que $33 \%$ da microbiota fúngica da mama é representada pelas mes- mas leveduras (1), o que confirma o caráter oportunista das mesmas. Do microrganismo isolado parece não existir informaçōes de sua participaçāo na microbiota fúngica da mama bovina,embora seu comportamento biológico em parasitismo tenha sido análogo ao de outras leveduras do gênero. No que se refere a identificação do mesmo, é de se ressaltar seu comportamento bioquímico semelhante ao da levedura isolada por CARMO SOUZA ${ }^{(10)}$, o que nos permite caracterizá-la como Candida luzitanae.

RFMV-A/22

MÓS, E.N.; BIRGEL, E.H.; MENDES, M.J.S. Bovine mastitis by yeast of the Candida genus.Rev. Fac. Med. Vet. Zootec. Univ. S. Paulo, 15 (2): 16I-64, 1978

SUMMARY: The authors present a case of mastitis in a eight years old, black and white Holandish cow, imported from Canada and presenting high production. Antecedents were: traumatism at the mammarygland level, with increase in volume and mamitis of the right hind quarters.After treatment with oxaciline for five(5)days, there was an exacerbation of the symptoms. Diagnosis was established by cultivation of material from the quarters, confirming mamitis caused by yeast of the genus Candida. Parcial results from the biochemical data suggest the presence of Candida luzitanae.

UNITERMS: Mastitis, bovines*; Candida luzitanae, Yeasts*.

\section{REFERENCIAS BIBLIOGRAFICAS}

1 - ALVARES H \& FLORES, C. Flora Micologia en leche de vacas sanas y con mastites. Rev. Soc. Med. Vet. de Chile, 12 (3): 11-17, 1962

2 - BENITO-TRUJILLO, A.; BORREI, A.J. \& OGER, C. Sur la présence de levures dans les laits pathologiques. Rev. Med. Vet., 106: 586-92, 1955

3 - DORNER, W.; DEMONT \& CHAVAN NE, D. Microbiologia.Laitière. Paris, La Maison Rustique, p. $75,1951$.

4 - EMMONS, C W ; BINFORD, C.H \& UTZ, J.P. Medical Mycology,. $2^{\mathrm{a}}$ ed. Lea \& Febiger, Philadelphia, p. 178 , 1971

5- GUILHON, J.; CHARTON, A.; DROUHET, E.; KHAN, J. LECOANET, J. Mammite de la vache due à Candida pseudotropicalis. Bull. Acad. vét. France, 34: 367-70. 1961 .

6- HEIDRICH, H J \& RENCH, W. Enfermidades de las glandulas mamarias en los animales domesticos. Barcelona, Ed. Labor, S.A. p. 1,1969.

7 - HOFMAN, W.; IMMER, J. \& LANZ, E. Die Pilzmastitis beim RIND. Wien tieräztl. Machr., 52(5): 385-91, 1965

8 - LACAZ et alii Curso sobre aspectos fundamentais de Micologia Médica. São Paulo, Inst. de Med. Trop. de S. Paulo e Inst. Ciências Biomédicas da U.S.P., 1973. p. 75-81

9 - LEMAU, C. SHAPIRO \& ASCHMER, $M$. Yest infection of the udder after irrigation with penicilin. In: Schalm O.W.; Carrol; E.J. Chain, N.C Bovine Mastitis. Philadelphia, Lea \& Febiger. p. $360,1971$.

10 - LODDER, J. The yeasts a taxonomic study. Amsterdan, North Publishing Co., 1971

11 - LOFTSGARD, G.\& LINDQVIST, K. Bovine Mycotic Mastitis. Acta Vet. Scand. I(3): 201-20, 1960

12 - RIMBAUD,P.\&RIOUX, J.A. Les monilioses au cours des traitements par les antibiotiques. Conceptions pathogéniques. Presse Med., 63 (34): 701 , 1955.

13 - SCHALM, O.W. CARROLL, E.J. \& CHAIN, N.C. Bovine Mastitis. Philadelphia, Lea \& Febiger, p. 360, 1971. 